\title{
Effects of exogenous Fibroblast Growth Factor-21 on characteristic parameters related to energy metabolism in dairy cows ${ }^{1)}$
}

\author{
YUANYUAN CHEN, QIAN WU, YING GAO, HONGTAO ZHANG, \\ ZHIHAO DONG, RUIRUI LI, CHUANG XU
}

\author{
College of Animal Science and Veterinary Medicine, Heilongjiang Bayi Agricultural University, \\ Daqing High-tech Industrial Development Zone, Daqing 163319, PR China
}

\section{Chen Y., Wu Q., Gao Y., Zhang H., Dong Z., Li R., Xu C. \\ Effects of exogenous Fibroblast Growth Factor-21 on characteristic parameters related to energy metabolism in dairy cows}

Summary

Negative energy balance (NEB) is a common pathological foundation of fatty liver and ketosis. Liver and fat tissue are the major organs of lipid metabolism, which is also a key metabolic pathway that regulates NEB development during the perinatal period. Fibroblast growth factor-21 (FGF-21) is a protein hormone that plays an important role in adipose lipid metabolism and liver gluconeogenesis. Our aim was to investigate the effects of exogenous FGF-21 on characteristic parameters related to energy balance in dairy cows. Ten non-pregnant, non-lactating Holstein-Friesian dairy cows were randomly allocated into two groups. The interventions were exogenous FGF-21 injection group received $1 \mathrm{ug} / \mathrm{kg}$ BW (body weight) of recombinant bovine FGF-21 by intravenous injection, and control group received physiological saline injections by intravenous injection. In comparison to saline injections, intravenous injections of FGF-21 either increased or tended to increase concentrations of FGF-21 $(p<0.05)$, BHBA $(p<0.05)$, adiponectin, leptin and HDL-C. FGF-21 injections decreased or tended to decrease concentrations of insulin, glucose, glucagon $(p<0.05)$, ALT/GPT $(p<0.05)$, AST/GOT $(p<0.05)$, urate, creatinine $(p<0.05)$, BUN, triglyceride $(p<0.05)$, T-CHO and LDL-C $(p<0.05)$. The results indicate that FGF-21 has only negative effects on the metabolites and metabolic hormones related to NEB in serum of dairy cows, but it has more beneficial effects on prominent adipokines, liver function index, renal function index, lipoprotein profiles related to the pathological changes that occurred in NEB.

Keywords: exogenous FGF-21, negative energy balance, serum metabolites

Energy metabolism disorder has a serious effect on the dairy cattle industry during the transition period and can lead to severe economic losses. During the perinatal period the feed transferred from low-energy to high-energy leads to nutritional stress and a decrease in dry matter intake, whereas an increased energy demand is a cause of negative energy balance (NEB). Glucose and dexamethasone are widely used for the treatment of NEB. But there are some side effects in the clinical application of glucose, such as the reduction of insulin due to increased blood sugar, inhibiting the liver gluconeogenesis and appetite. Dexamethasone is an adrenal cortical hormone. Dexamethasone can promote glucose production and the production duration is from 2 day to

This study was supported by the major project of application technology research and development plan of Heilongjiang province (GA16B202) and the National Key Technology Support Program (2017YFD0502200).
4 days. But dexamethasone has an immunosuppressant effect and even can lead to miscarriage. FGF21 neither promotes cell proliferation nor antagonizes other members of the FGF family, thereby greatly reducing the risk of clinical medication.

FGF-21 was originally discovered as a new member of the FGF superfamily (7). Initially, FGF21 existed primarily in the liver and the blood, which mainly acted on the adipose tissue, thus the researchers inferred that FGF21 was a hormone closely related with the liver and adipose tissue. However, FGF21 is expressed mainly in the liver, pancreas and adipocytes. It plays biological functions in these tissues and maintains intertissue interconnections, thus revealing that FGF21 may play a role as an autocrine/paracrine cytokine. FGF-21 plays a key regulatory role in the relationship between stimulating protein, glucose and lipid metabo- 
lism, and energy balance $(1,2)$. Recent studies show that systemic administration of recombinant FGF-21 to cultured cells (5), rodents (4), and primates $(3,10)$ improves glucose and lipid metabolism, suggesting that FGF-21 might be an interesting candidate for treating diabetes and other metabolic dysregulations clustered in animals with a metabolic syndrome (6). However, FGF-21 has obvious species specificity, and research on FGF-21 in dairy cows is limited compared with that in humans and other mammals. Studies show that the level of FGF-21 increases rapidly in the postpartum period and is maintained at a lower level during the perinatal period $(8,9)$. Our hypothesis was that FGF21 administration leads to changes in the dynamics of characteristic parameters related to energy metabolism in dairy cows. To address the hypothesis, we measured serum concentrations of metabolites and metabolic hormones (BHBA, insulin, glucose, glucagon), adipokines(adiponectin, leptin), organ function indexes (ALT/GPT and AST/GOT, urate, creatinine and urea nitrogen) and lipoprotein profiles (HDL-C, triglyceride, T-CHO and LDL-C). Thus, we could speculate the role of exogenous FGF-21 in NEB on the basis of its effect to energy metabolism.

\section{Material and methods}

Animal Ethics Committee. This study was approved by the National Institute of Animal Health Animal Care and Use Committee at Heilongjiang Bayi Agricultural University (approval number 2017-015).

Herd and cow selection. In northeastern China (MiShan, Heilongjiang, China), commercial dairy herds from a large dairy farm $(n=2160)$ were selected to participate in the study. Ten non-pregnant, non-lactating Holstein-Friesian heifers (18 \pm 4 months of age) were allocated randomly based on the specific conditions of compliance with the study protocol. All heifers were free of fever, abomasal displacement, mastitis, metritis, vaginal discharge, and bone fractures.

Recombinant FGF-21 protein. Recombinant FGF-21 protein used in the experiment was Recombinant Bovine FGF-21 (ProSpec-Tany TechnoGene Ltd, Hamerkaz, Israel; Catalog Number: CYT-657).

Animal management. All cows in this study were fed a total mixed ration (TMR) at 05:00, 14:00 and 20:00 hr. The TMR consisted of $55.60 \%$ dry matter (DM), $16.00 \%$ crude protein, $34.30 \%$ neutral detergent fiber, $22.00 \%$ acid detergent fiber, $5.60 \%$ fat, $1.07 \%$ calcium, $0.49 \%$ phosphorus, $0.32 \%$ magnesium, $0.13 \%$ sodium, $1.40 \%$ potassium, $0.39 \%$ chloride and $0.22 \%$ sulfur. This study included ten Holstein cows: five dairy cows were assigned randomly to each of two groups for the experiment. The exogenous FGF-21 injection group received $0.33 \mathrm{~mL}$ of recombinant bovine FGF-21 $(1 \mu \mathrm{g} / \mathrm{kg} \mathrm{BW})$ by intravenous injection, the control group received $0.33 \mathrm{~mL}$ of physiological saline injection $(1 \mu \mathrm{g} / \mathrm{kg} \mathrm{BW})$ by intravenous injection.

Sample collection. Blood samples were collected from the tail vein from 5:00 to 21:00. The experimental period was $16 \mathrm{~h}$, with blood samples collected every $2 \mathrm{~h}$ from the tail vein in tubes without anticoagulant. Blood samples were collected using an Abbocath-T Radiopaque FEP I.V. Catheter, 14G $\times 140 \mathrm{~mm}$, Model No. C5424535-27 (Hospira Inc., Lake Forest, IL, USA) and the indwelling needles were placed into the jugular vein 1 day before the start of the experiment. Tubes were placed in an icebox and transferred to the laboratory within $1 \mathrm{~h}$ of collection, after which they were placed at room temperature for $30 \mathrm{~min}$, centrifuged at $3000 \mathrm{~g}$ for $15 \mathrm{~min}$, and then stored at $20^{\circ} \mathrm{C}$ until analysis.

Data collection and statistical analyses. Data were collected and initially analyzed using Excel 2013 (Microsoft Corp. Redmond, WA). Descriptive and graphical analyses were performed to verify the data. When appropriate, IBM SPSS22.0 software (SPSS Inc., Chicago, IL) was used to analyze the data. The results are expressed as the mean \pm standard error means (SEM). Changes in FGF-21 levels and hormonal parameters between the two groups were evaluated by an Independent Sample T-test.

\section{Results and discussion}

Compared with a saline injection, an intravenous injection of FGF-21 either increased or tended to increase the concentration of FGF-21, $\beta$-hydroxybutyrate $(\beta$-HBA), adiponectin and leptin. FGF-21 injection decreased or tended to decrease the concentration of insulin, glucose, and glucagon (Tab. 1). These results indicated that intravenous injections of FGF-21 may play an important role in improving insulin resistance and lipid metabolism in dairy cows. Compared with saline injections, intravenous injections of FGF-21 either increased or tended to increase the concentration of high density lipoprotein cholesterol (HDL-C) and

Tab. 1. Effects of exogenous FGF-21 on serum levels of metabolites, metabolic hormones, prominent adipokines, liver function index, renal function index and lipoprotein profiles in dairy cows (mean $\pm S E M ; n=5)$

\begin{tabular}{|l|c|c|}
\hline \multicolumn{1}{|c|}{ Parameter studied } & Saline & FGF-21 \\
\hline$\beta$-HBA $(\mu \mathrm{mol} / \mathrm{L})$ & $615.81 \pm 62.52$ & $831.30 \pm 45.54^{*}$ \\
\hline Glucose $(\mathrm{mmol} / \mathrm{L})$ & $86.52 \pm 4.03$ & $64.66 \pm 4.07^{*}$ \\
\hline Insulin $(\mathrm{mlU} / \mathrm{L})$ & $13.66 \pm 0.76$ & $10.57 \pm 0.68^{*}$ \\
\hline Glucagon $(\mathrm{pg} / \mathrm{ml})$ & $591.16 \pm 15.71$ & $508.17 \pm 23.53^{*}$ \\
\hline FGF-21 $(\mathrm{pg} / \mathrm{ml})$ & $724.31 \pm 17.99$ & $854.48 \pm 28.07^{*}$ \\
\hline Adiponectin $(\mu \mathrm{g} / \mathrm{mL})$ & $30.10 \pm 1.07$ & $34.18 \pm 0.51^{*}$ \\
\hline Leptin $(\mu \mathrm{g} / \mathrm{L})$ & $261.30 \pm 11.15$ & $303.62 \pm 7.53^{*}$ \\
\hline ALT $(\mathrm{U} / \mathrm{L})$ & $20.13 \pm 1.31$ & $16.06 \pm 0.60^{*}$ \\
\hline AST $(\mathrm{U} / \mathrm{L})$ & $86.52 \pm 4.03$ & $64.66 \pm 4.07^{*}$ \\
\hline Urate $(\mathrm{mg} / \mathrm{L})$ & $4.92 \pm 0.08$ & $4.08 \pm 0.14^{* *}$ \\
\hline Creatinine $(\mu \mathrm{mol} / \mathrm{L})$ & $87.20 \pm 3.76$ & $60.83 \pm 4.18^{* *}$ \\
\hline BUN $(\mathrm{mmol} / \mathrm{L})$ & $6.82 \pm 0.37$ & $5.61 \pm 0.26$ \\
\hline Triglyceride $(\mathrm{mmol} / \mathrm{L})$ & $0.105 \pm 0.003$ & $0.090 \pm 0.003^{*}$ \\
\hline T-CHO (mmol/L) & $3.257 \pm 0.169$ & $3.050 \pm 0.313$ \\
\hline LDL-C $(\mathrm{mmol} / \mathrm{L})$ & $0.977 \pm 0.029$ & $0.771 \pm 0.055^{*}$ \\
\hline
\end{tabular}

Explanations: * Compared with saline group at each time point $\mathrm{p}<0.05, * *$ Compared with saline group at each time point $\mathrm{p}<0.01$ 
decreased or tended to decrease the concentration of triglyceride, total cholesterol (T-CHO), and low density lipoprotein-cholesterol (LDL-C) (Tab. 1). These results showed that exogenous FGF-21 may play an important role in improving hyperlipidemia and hypercholesterolemia in dairy cows. Studies have shown that FGF-21 has the same effect in diabetic monkeys, which can lower serum levels of LDL-C but increase HDL-C. FGF-21 plays an important role in regulating of the metabolism in rodents and non-primates. These findings support our results that FGF-21 administration improved lipoprotein profiles, including lowering LDL-C and raising HDL-C, and it had beneficial effects on the circulating levels of NEB risk markers/factors.
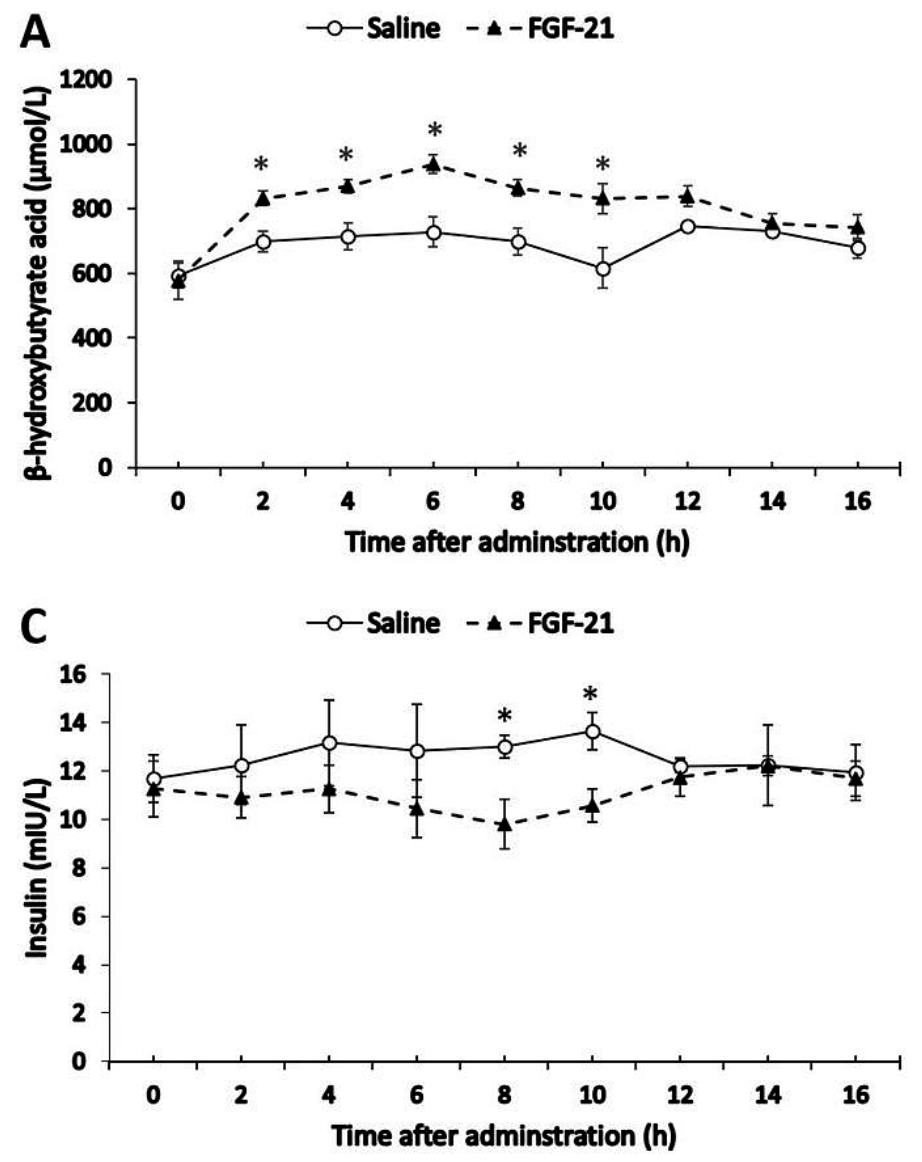

These data support the development of FGF-21 for the treatment of dairy cows with NEB.

Compared with saline injections, FGF-21 injections decreased or tended to decrease concentrations of AST and ALT (Tab. 1). AST and ALT are mainly expressed in liver and muscle cells and play a role in the metabolism of amino acids and carbohydrates. Human studies showed that serum FGF-21 levels are significantly higher in non-alcoholic fatty liver disease patients than in healthy controls, and FGF-21 levels in serum are associated with AST and LDL-C $(\mathrm{P}<0.05)$, suggesting the possibility of a direct positive metabolic effect of FGF-21 in humans. In our study, we showed that exogenous FGF-21 significantly improved liver
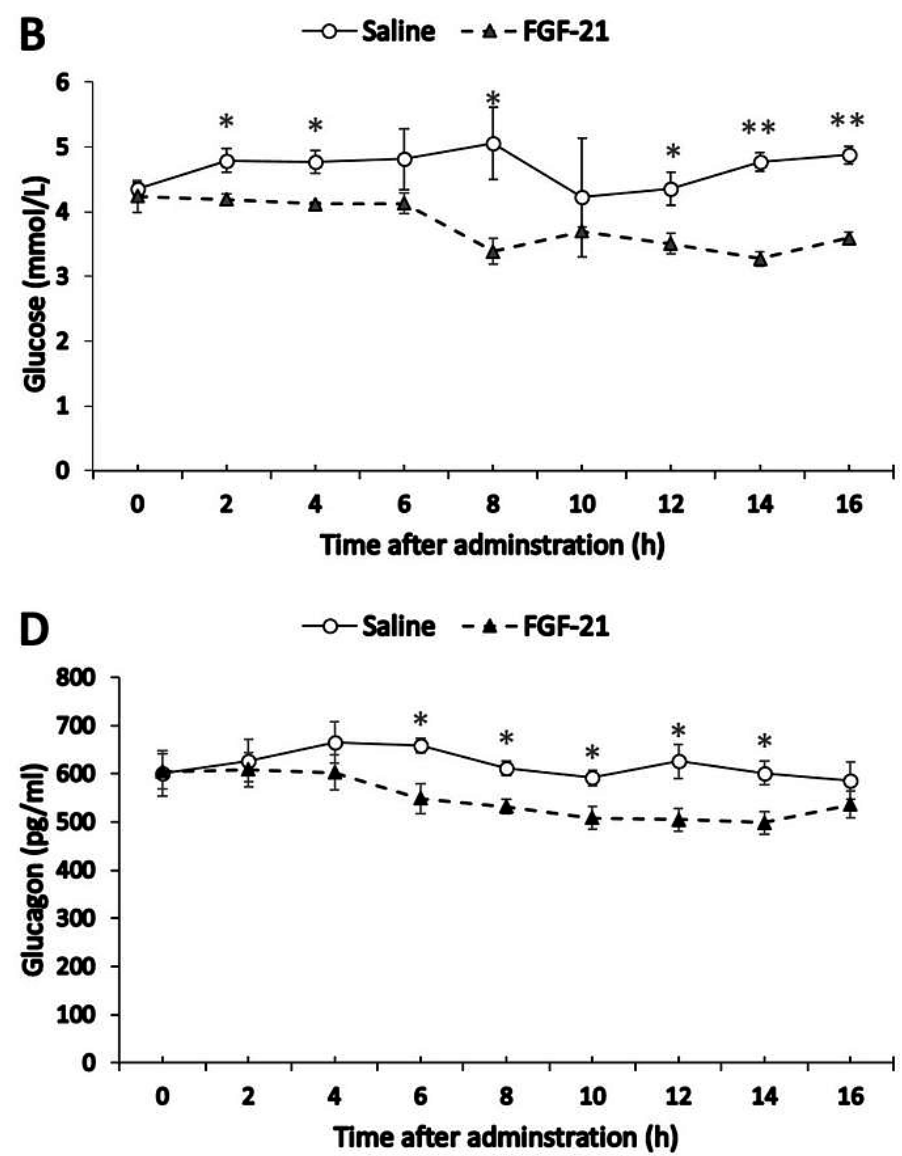

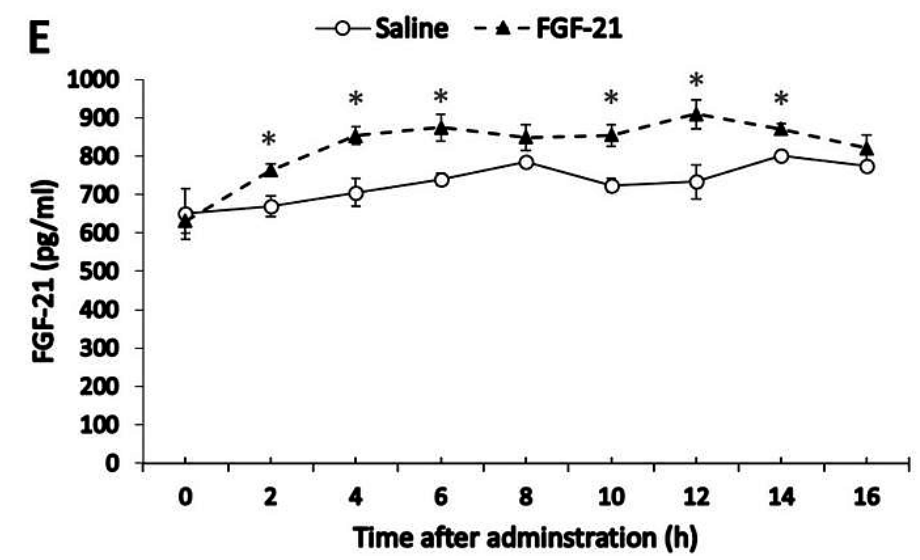

Fig. 1. Effects of exogenous FGF-21 on serum levels of metabolites, metabolic hormones, and FGF-21 in dairy cows (mean \pm SEM; $n=5$ ). Effects of FGF-21 on serum levels of (A) BHBA, (B) glucose, (C) insulin, (D) glucagon, and (E) FGF-21 Explanations: $* \mathrm{p}<0.05, * * \mathrm{p}<0.01$ versus the saline group at each time point 
function indexes. Compared with the normal controls, the activity or serum levels of AST and ALT decreased significantly in the exogenous FGF-21 treated group in our study.

Compared with saline injections, FGF-21 injections decreased or tended to decrease the concentration of urate, creatinine, and blood urea nitrogen (BUN) (Tab. 1). Urea nitrogen is the main end product of protein catabolism. BUN is derived from the liver and the kidney is its metabolic outlet. Serum values of BUN can be regarded as an essential index of protein catabolism (Chikhou et al., 1993). Creatinine is a product of muscle tissue metabolism, which reflects the damage status of the kidney and muscle. We measured renal function indexes to determine whether the serum FGF-21 levels observed in this study were significant and calculable. However, renal function indexes decreased significantly after the administration of exogenous FGF-21. Lower BUN and creatinine concentrations indicate a higher nitrogen utilization efficiency, and the increased values of BUN and creatinine in the serum could indicate a severe increase of protein catabolism. The results indicated that exogenous FGF-21 had the ability to improve the efficiency of nitrogen utilization.

Serum metabolites, metabolic hormones, FGF-21, adipokines, liver function index, renal function index and lipoprotein profiles were measured at $0 \mathrm{~h}$, 2 h, 4 h, 6 h, 8 h, 10 h, 12 h, 14 h, 16 h, respectively. With the prolonging of time, serum concentrations of FGF-21, $\beta$-HBA, adiponectin, leptin, and HDL-C in FGF-21 group cows increased or tended to increase (Fig. 1, 2, 5), but insulin, glucose, glucagon, ALT, AST, urate, creatinine, BUN, triglyceride, $\mathrm{T}-\mathrm{CHO}$ and LDL-C decreased or tended to decrease (Fig. 1, 3, 4, 5). There were fluctuation changes of serum adipokines, liver function index, renal function index concentrations at different time points after intravenous injections of FGF-21 of cows in test groups.

These results of the present study indicated that FGF21 maybe have potential therapeutic value in dairy cows with a negative energy balance.
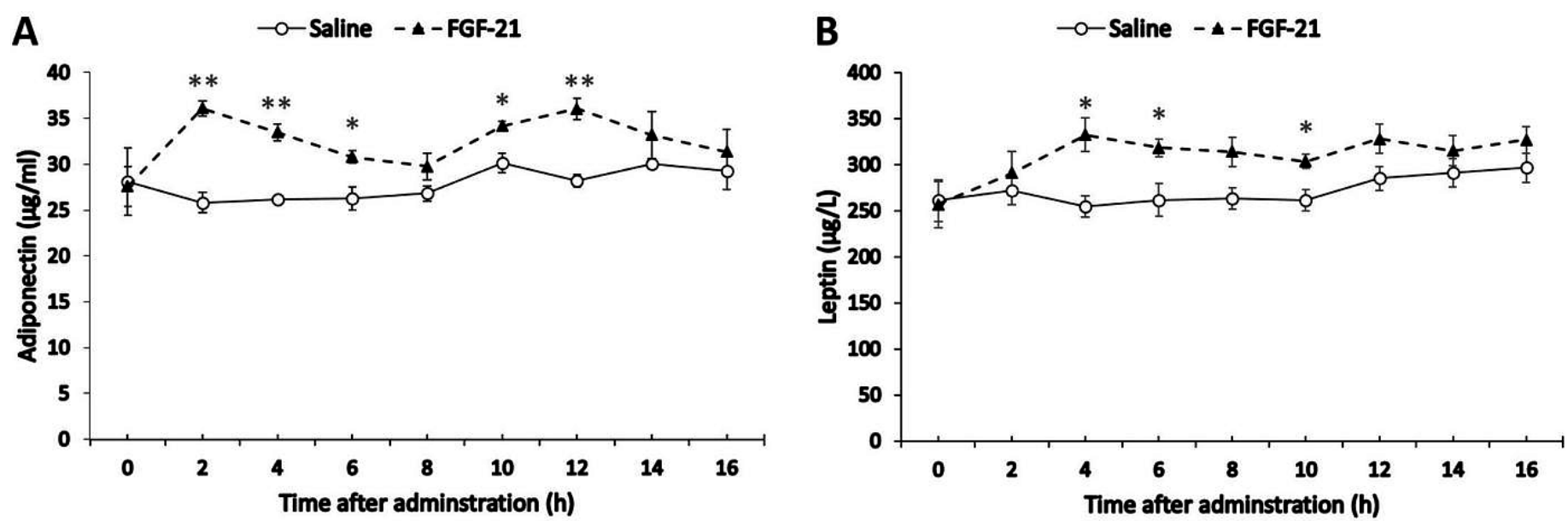

Fig. 2. Effects of exogenous FGF-21 on serum levels of prominent adipokinesin dairy cows (mean $\pm \mathbf{S E M}$; $\mathbf{n}=\mathbf{5}$ ). Effects of FGF-21 on serum levels of (A) adipokine and (B) leptin Explanations: as. in. Fig. 1.
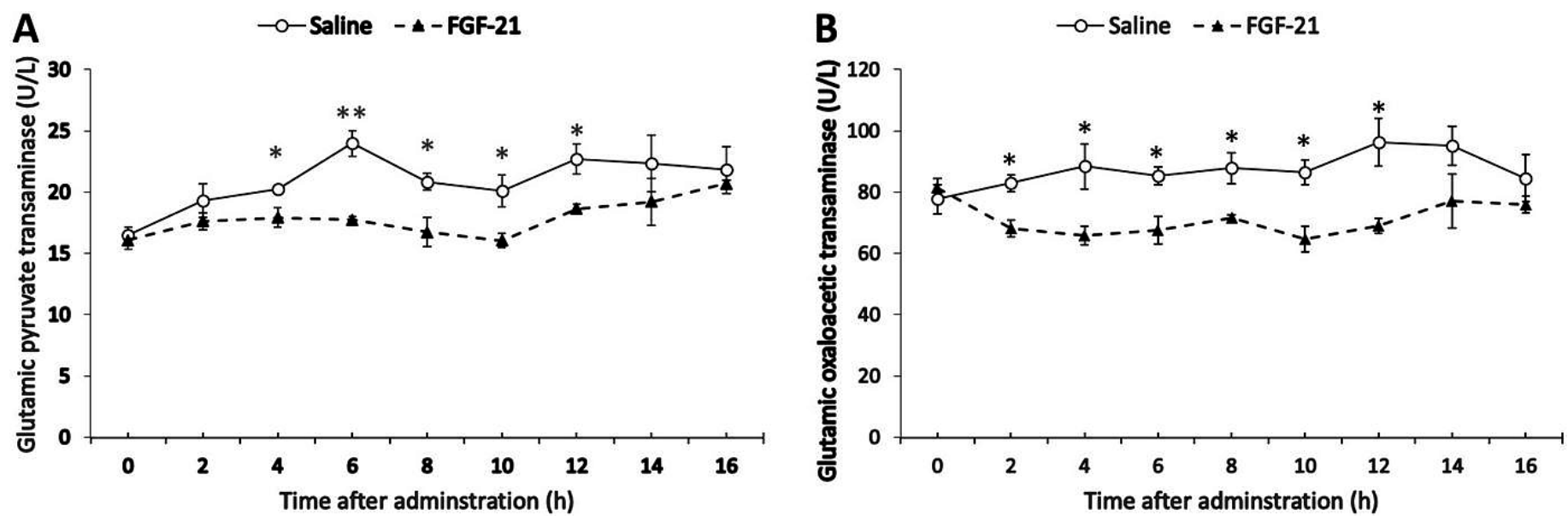

Fig. 3. Effects of exogenous FGF-21 on liver function index markers in dairy cows (mean \pm SEM; $n=5)$. Effects of FGF-21 on serum levels of (A) ALT and (B) AST

Explanations: as. in. Fig. 1. 

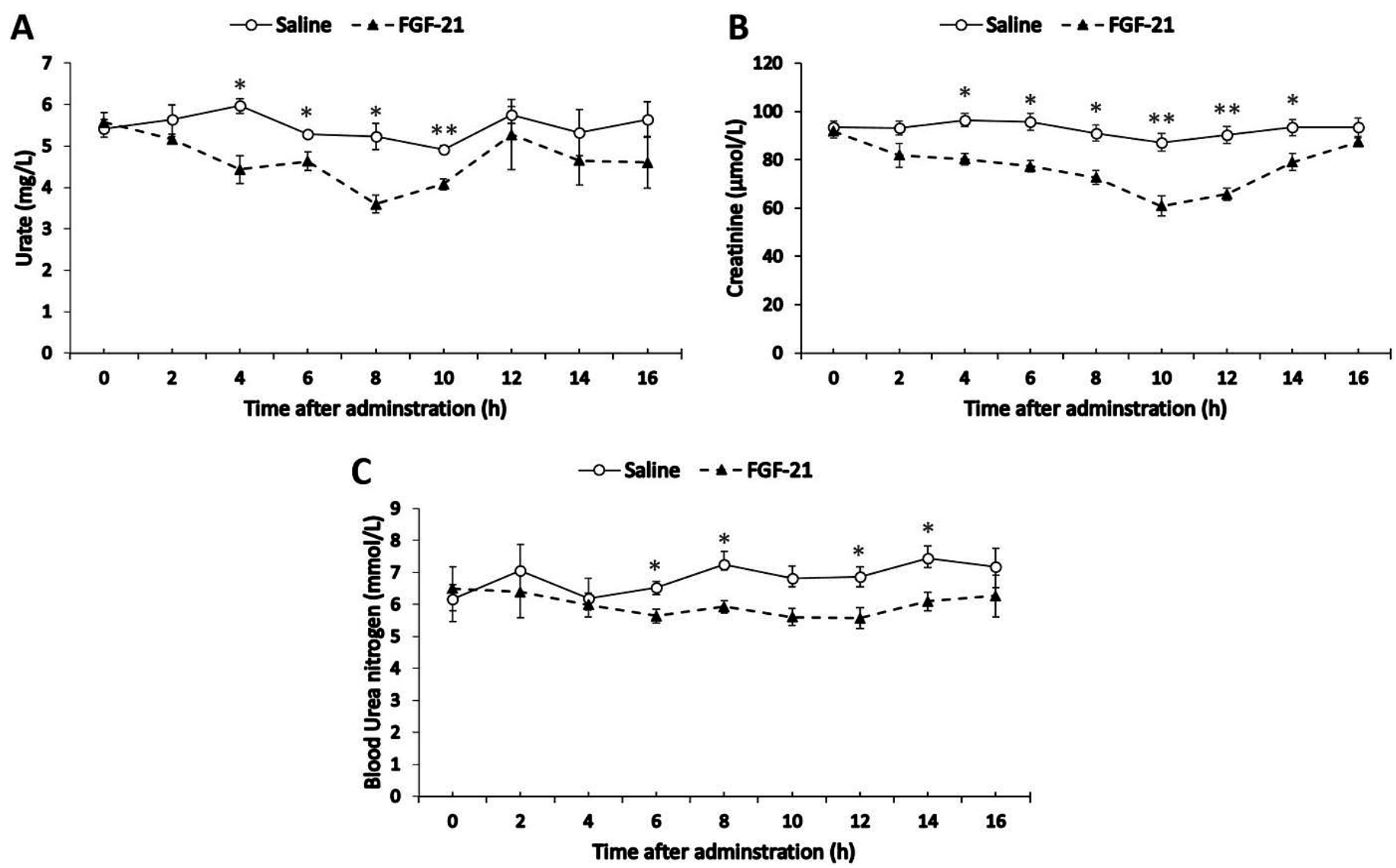

Fig. 4. Effects of exogenous FGF-21 on renal function index markers in dairy cows (mean \pm SEM; $n=5)$. Effects of FGF-21 on serum levels of $(A)$ urate, $(B)$ creatitine, and $(C)$ blood urea nitrogen

Explanations: as. in. Fig. 1.
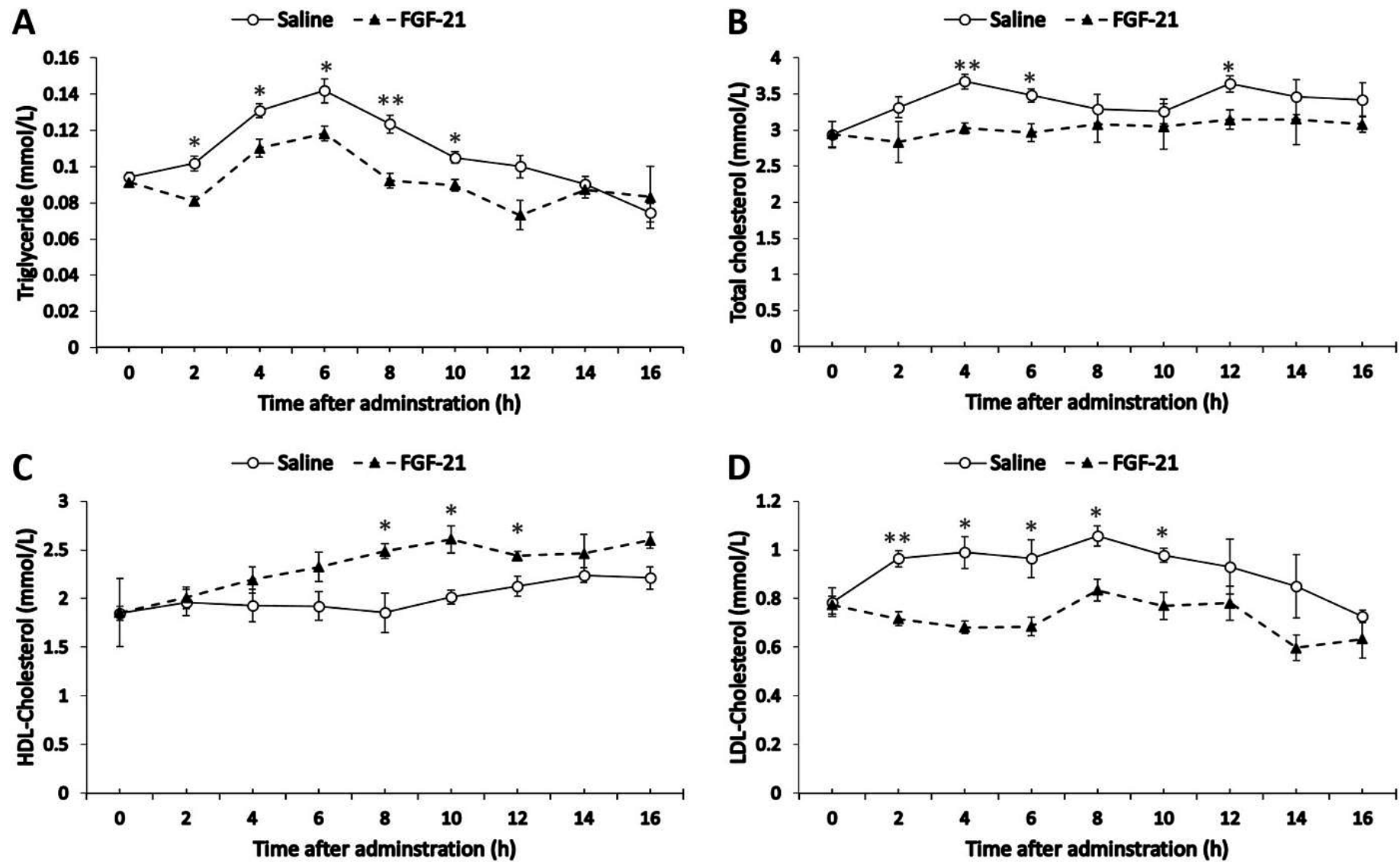

Fig. 5. Effects of exogenous FGF-21 on lipoprotein profiles in dairy cows (mean \pm SEM; $n=5$ ). Effects of FGF-21 on serum levels of (A) triglyceride, (B) total cholesterol, (C) HDL-C, and (D) LDL-C

Explanations: as. in. Fig. 1. 


\section{References}

1. Chikhou F. H., Moloney A. P., Allen P., Quirke J. F., Austin F. H., Roche J. F.: Long-term effects of cimaterol in friesian steers: i. growth, feed efficiency, and selected carcass traits. J. Anim. Sci. 1993, 71, 906-913.

2. Coskun T., Bina H. A., Schneider M. A., Dunbar J. D., Hu C. C., Chen Y., Moller D. E., Kharitonenkov A.: Fibroblast growth factor 21 corrects obesity in mice. Endocrinology 2008, 149, 6018-6027.

3. Esteghamati A., Khandan A., Momeni A., Behdadnia A., Ghajar A., Nikdad M. S., Noshad S., Nakhjavani M., Afarideh M.: Circulating of levels fibroblast growth factor 21 in early-stage diabetic kidney disease. Irish J. Med. Sci. 2017, 186, 1-10.

4. Kharitonenkov A., Larsen P.: FGF21 reloaded: challenges of a rapidly growing field.: Trends Endocrinol. Metabolism 2011, 22, 81-86.

5. Kharitonenkov A., Shiyanova T. L., Koester A., Ford A. M., Micanovic R., Galbreath E. J., Sandusky G. E., Hammond L. J., Moyers J. S., Owens R. A., Gromada J., Brozinick J. T., Hawkins E. D., Wroblewski V. J., Li D. S., Mehrbod F., Jaskunas S. R., Shanafelt A. B.: Fgf-21 as a novel metabolic regulator.: J. Clin. Invest. 2015, 115, 1627-1635.

6. Mraz M., Bartlova M., Lacinova Z., Michalsky D., Kasalicky M., Haluzikova D. Matoulek M., Dostalova I., Humenanska V., Haluzik M.: Serum concentra- tions and tissue expression of a novel endocrine regulator fibroblast growth factor- 21 in patients with type 2 diabetes and obesity. Clin. Endocrinol. 2009 , 71, 369-375.

7. Nishimura T., NakatakeY., Konishi M., Itoh N.: Identification of a novel FGF, FGF-21, preferentially expressed in the liver. Biochim. Biophys. Acta 2000, 1492, 203-206.

8. Osorio J. S., Trevisi E., Ballou M. A.: Effect of the level of maternal energy intake prepartum on immunometabolic markers, polymorphonuclear leukocyte function, and neutrophil gene network expression in neonatal Holstein heifer calves. J. Dairy Sci. 2013, 96, 3573-3587.

9. Schoenberg K. M., Giesy S. L., Harvatine K. J.: Plasma FGF-21 is elevated by the Intense lipid mobilization of lactation. Endorinology 2011, 152, 4652-4661 .

10. Shenoy V. K., Beaver K. M., Fisher F. M., Singhal G., Dushay J. R., MaratosFlier E., Flier $S$. N.: Elevated Serum Fibroblast Growth Factor 21 in humans with Acute Pancreatitis. Plos One 2016, 11, e0164351.

Corresponding author: Chuang $\mathrm{Xu}$, professor of Clinical Veterinary Medicine, College of Animal Science and Veterinary Medicine, Heilongjiang Bayi Agricultural University, Industrial Development Zone, 163319 Daqing, China; e-mail: chuangxu7175@163.com 